\title{
Preeclampsia, Natural History, Genes, and miRNAs Associated with the Syndrome
}

\author{
Laura Parada-Niño $(\mathbb{D}$, Luisa Fernanda Castillo-León $(\mathbb{D}$, and Adrien Morel $\mathbb{1}$ \\ Center for Research in Genetics and Genomics-CIGGUR, GENIUROS Research Group, School of Medicine and Health Sciences, \\ Universidad del Rosario, Bogotá, Colombia \\ Correspondence should be addressed to Adrien Morel; adrien.morel@urosario.edu.co
}

Received 29 September 2021; Accepted 19 January 2022; Published 14 February 2022

Academic Editor: Olav Lapaire

Copyright (c) 2022 Laura Parada-Niño et al. This is an open access article distributed under the Creative Commons Attribution License, which permits unrestricted use, distribution, and reproduction in any medium, provided the original work is properly cited.

\begin{abstract}
Preeclampsia (PE) is a hypertensive disease that affects pregnant women after 20 weeks of gestation. This disease is associated with an important risk of maternal and fetal mortality. PE is described as a placental pathology because, after delivery, most women recover normal arterial pressure. Poor invasion of the spiral arteries is a phenomenon well described in PE; this leads to a hypoxic uterine bed and imbalance of antiangiogenic and proangiogenic factors in the uteroplacental region, which in turn triggers the disease phenotype. The causes of the pathology are unclear; nevertheless, numerous approaches, including nextgeneration sequencing, association, and case control and miRNA studies, have shed light on the genetic/molecular basis of PE. These studies help us better understand the disease to advance new treatment strategies.
\end{abstract}

\section{Introduction}

The pregnancy-specific multisystem syndrome known as preeclampsia (PE) affects $2 \%-10 \%$ of all gestations and is a major cause of perinatal morbidity and mortality worldwide $[1,2]$.

This disease is diagnosed above 20 weeks of gestation and is characterized usually by the presence of de novo arterial high blood pressure $\geq 140 / 90 \mathrm{mmHg}$ (also can be superimposed with chronic hypertension), associated or not with proteinuria [3] (Figure 1(a)). Without proteinuria, the disease is diagnosed with signs of target organ damage such as serum creatinine concentration $>1.1 \mathrm{mg} /$ dLor with double the baseline value in the absence of renal disease, thrombocytopenia $<100.000 \mathrm{plt} / \mu \mathrm{L}$, elevation of liver transaminases to twice the normal value, pulmonary edema, or symptoms of visual or cerebral disturbance [4, 5]. Women with preeclampsia have a potentially lifethreatening condition, because this disease is associated with an increased risk of developing long-term complications such as cardiovascular disease $[6,7]$.

\section{History of the Disease}

The etiology of PE is still unclear, but studies on this topic involve the placenta in the pathophysiology, among other reasons, because it has been shown that after delivery, the signs and symptoms of the disease mostly disappear [8]. There are two subtypes of $\mathrm{PE}$, an early-onset preeclampsia, also known as placental type, present in as much as $20 \%$ of $\mathrm{PE}$ cases and characterized by the presence of signs and symptoms before 34 weeks of gestation. This subtype has been widely linked to fetal growth restriction (FGR) [9]. Early-onset PE is characterized by abnormal trophoblastic invasion, due to incomplete transformation of the spiral arteries, leading to placental ischemia, a subsequent inflammatory response, and exacerbated oxidative stress (Figure 1(b)). All these factors contribute to a systemic imbalance of antiangiogenic and proangiogenic factors that trigger the clinical syndrome [10]. Vascular endothelial growth factor (VEGF), endoglin, and placental growth factor (PlGF) are angiogenic factors of major relevance regarding the etiology of preeclampsia [11]. On the other hand, the 
late-onset preeclampsia, also known as maternal subtype, develops after 34 pregnancy weeks and represents $80 \%$ of all $\mathrm{PE}$ cases. It has been proposed that this subtype is the consequence of a maternal genetic predisposition to cardiovascular and metabolic diseases, associated with chronic systemic inflammation combined with an altered relation between maternal blood perfusion and the increased metabolic demands from the placenta and the fetus. These disturbances can lead to placental dysfunction and associated placental hypoperfusion, without poor placentation, as seen in early-onset preeclampsia $[9,12]$.

Currently, prophylactic treatment with low-dose aspirin $(<100 \mathrm{mg} /$ day) is the conventional therapy for preventing the onset of signs and symptoms, as well as complications related to preeclampsia. Prophylactic treatment beginning before 16 weeks of gestation can reduce PE incidence and rate of complications by up to $70 \%$ [13].

\section{Association Studies}

Preeclampsia (PE) is a multifactorial pregnancy-specific syndrome without a Mendelian inheritance pattern [14-17]. It is the consequence of complex interactions between two or more maternal and fetal genes, in addition to the environment [18]. Several pedigree analyses in different populations reveal clear heritability, which is estimated between $31 \%$ and $54 \%$ [19-21]. 35\% of the variation in PE can be attributed to maternal genetics, $20 \%$ to fetal genetics, $13 \%$ to paternal genetics, and $32 \%$ to environmental factors [22].

Currently, the etiology of PE is not clear; therefore, several association studies have been developed, including the study of candidate genes, genome-wide association studies (GWAS), and linkage to identify susceptibility genes to PE [14, 23-26]. However, a limitation of these studies is that they are mainly focused on analyzing the mother, even though it is a disease involving genetic factors of both parents.

Candidate gene studies have compared the frequency of genetic variations between cases and controls to determine genetic associations. Most studies analyze a single polymorphism in a candidate gene, while a minority analyzes several genes or multiple polymorphisms in one or more genes. These genes have been selected based on the current understanding of PE pathology $[11,24]$, such as genes involved in endothelial functions and related with blood pressure regulation and key genes involved in the regulation of blood pressure: $s$ VEFGR-1, TGF- $\beta$, Eng, RAS, AGT, ACE, AGTR1 $[27,28]$, and $e N O S[29,30]$; genes that regulate lipid metabolism and oxidative stress: EPHX1 [31, 32], GST, NOX1, SOD2 [18, 33], APOE [27], LPL [34], and ROS [35, 36]; and thrombophilic genes involved in coagulation: F5, F2, and MTHFR [27, 28, 37-39]. As previously described, PE can be caused by genetic factors from both parents, an observation supported by Andraweera et al. and Zusterzeel et al., who found that variants present in the father, more precisely in the VEGF, PIGF, and GST1 genes, can double the risk of PE $[40,41]$. Studies suggest that PE is an immune maladaptation due to the defective interaction between fetal antigens and maternal immune cells, limiting the establishment of immune tolerance to normal placentation. The genes TNF $\alpha[42,43], I F N-\gamma, I L-1, I L-4, I L-10$ [44-46], IL27 [47, 48], HLA-G, TGF- $\beta, E, H L A-C 2$, and KIR are involved in this immune response (Table 1).

Genetic mapping and linkage studies conducted in family pedigrees have identified chromosomal regions associated with $\mathrm{PE}$ in all chromosomes, with chromosome 2 having the highest number of loci involved. For example, ACVR2 and STOX1, the two most studied candidate genes, were identified using genetic linkage methods. The first was identified in a case-control study in which Moses and collaborators found a $>10$-fold differential gene expression in decidua samples between PE and normotensive women [49]. For the second one, the analysis of 67 affected families showed an association between STOX1 and the disease [50].

Regarding GWAS, an approach designed to study case and control cohorts of unrelated individuals, multiple loci that can explain a portion of the variation in preeclampsia phenotypes have been identified (Table 2). For example, the inhibin beta $\mathrm{B}$ gene $(I N H B B)$, a pituitary folliclestimulating hormone secretion inhibitor that has been suggested to play a role in PE development [51], and the pregnancy-specific beta-1 glycoprotein 11 (PSG11) [49], which is mainly produced by placental syncytiotrophoblast during pregnancy, showed a high association. The MTHFR gene was associated with a protective effect against $P E$ in an association study where 816 nonpreeclamptic women were significantly less prone to develop preeclampsia than 1006 preeclamptic women [52]; with regard to an enzyme involved in the regulation of folate metabolism, McGinnis and collaborators performed the first GWAS study in a cohort of descendants composed of 4380 cases (631 early and 3749 late-onset PE) and 310,238 controls. They discovered a sequence variant in the fetal genome that may increase the risk for PE near to the sFlt1 gene, an antiangiogenic factor $[53,54]$. In this gene, the variant rs4769613 is a preeclampsia-specific risk factor, when present in the placenta genome but not directly in the parental genotype [53, 55]. However, the placental genotype for rs4769613 combined with clinical parameters may contribute to early identification of high-risk women and may provide insight into how altered expression relates to the pathophysiology of preeclampsia and its subtypes.

Another way to identify genes involved in the pathogenesis of a multifactorial disease such as PE is through microarray analysis to study the expression patterns of tens of thousands of genes simultaneously [14]. To date, these studies have been performed with RNA taken from placental biopsies in the second and third trimesters, placenta samples up to one hour after delivery, decidua tissue, and cytotrophoblast cultures (Table 3). These studies revealed that genes related to obesity, cytokine-receptor genes, and genes related to apoptosis could be potential susceptibility genes, based on the altered expression in preeclamptic compared with normotensive women $[56,57]$. Previous studies have shown that genes involved in activin/inhibin signalling (ACVR1, ACVR1C, ACVR2A, INHA, INHBB), structural components (COL4A1, COL4A2), and aminopeptidases (ERAP1, ERAP2, and $L N P E P$ ) were differentially expressed in the maternalfetal interface of PE pregnant women $[23,58]$. 


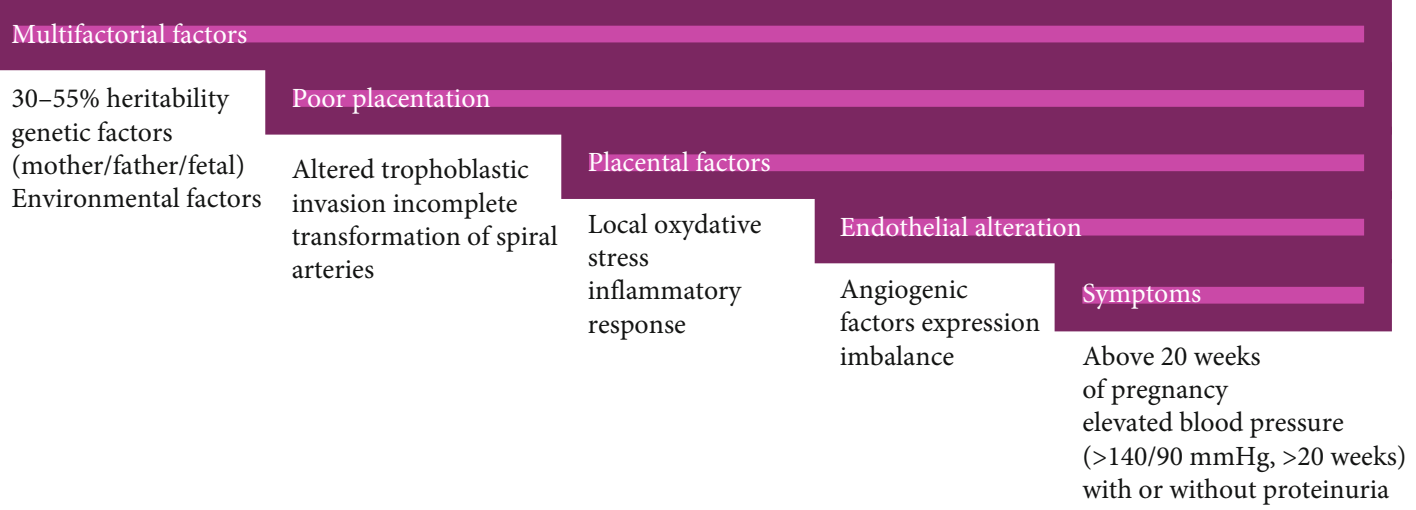

(a)

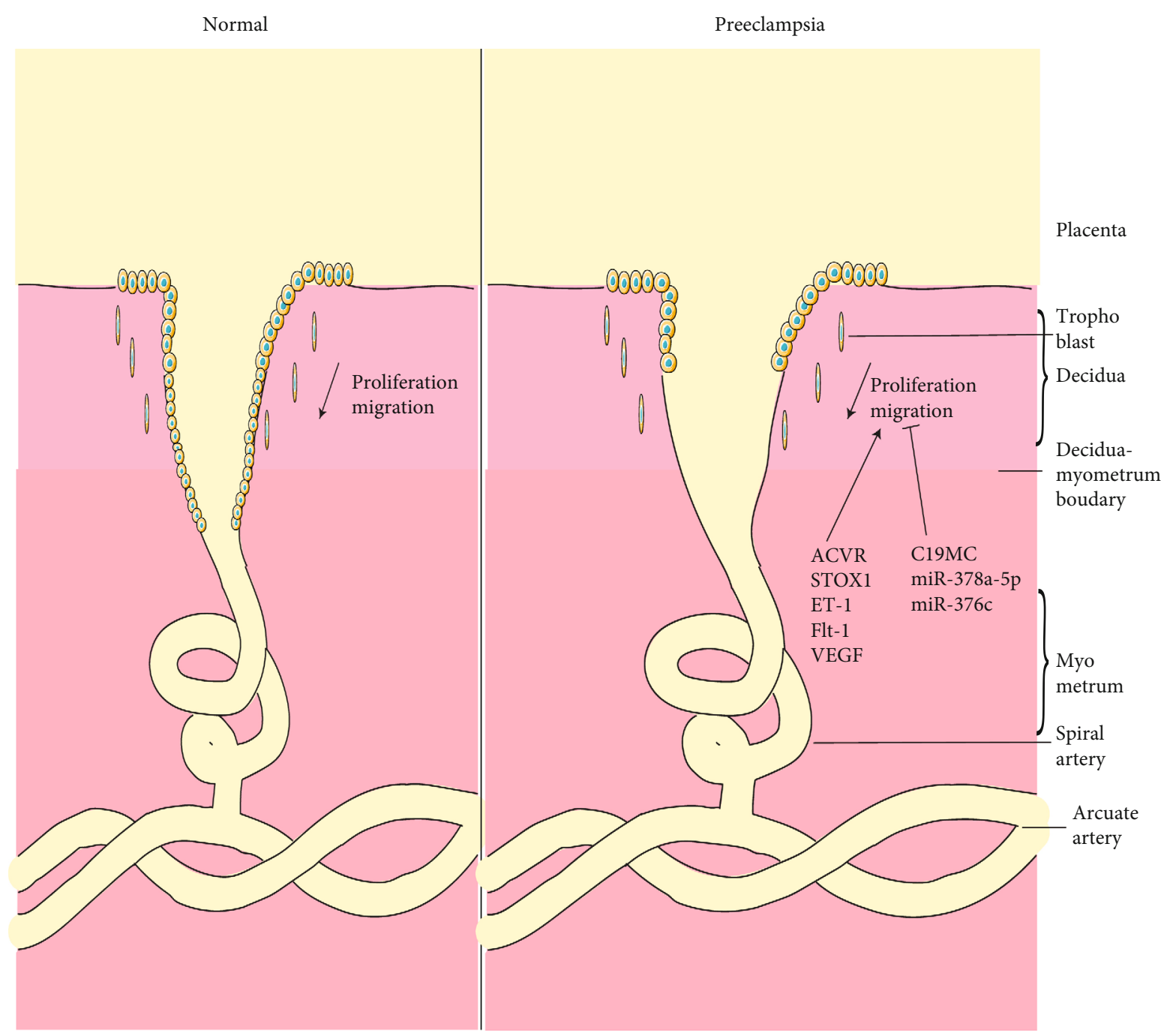

(b)

Figure 1: Key points of Preeclampsia (PE). A) Factors involved in PE. B) Deficient invasion of trophoblast in spiral arteries.

Despite the large number of candidate genes and associated loci identified as potential candidates, a universal susceptibility gene has not been found, principally due to the lack of reproducibility [14]. For example, there is substantial evidence suggesting the role of STOX1 as a potential PE susceptibility gene; linkage studies allowed a detailed analysis of this gene and several mutations were found and tested in in vitro and in vivo experiments, confirming that one of these variants could be a risk factor for PE [50]. Nevertheless, Iglesias-Platas et al. could not replicate these results [59]. Therefore, the experimental design should be standardized considering the case definition, sample size, and 
TABLE 1: Genes and SNPs associated with preeclampsia.

\begin{tabular}{|c|c|c|c|c|c|}
\hline Gene & SNP & $\begin{array}{l}\text { Study size (case/ } \\
\text { control) }\end{array}$ & $\begin{array}{c}\text { Sample } \\
\text { origin }\end{array}$ & Association & Reference \\
\hline \multirow[t]{2}{*}{ IL1RL1 } & rs1420103 & \multirow[t]{2}{*}{$214 / 208$} & \multirow[t]{2}{*}{ Mother } & $\begin{array}{c}\text { GG increases mild preeclampsia risk; TT reduces late- } \\
\text { onset severe preeclampsia }\end{array}$ & \multirow[t]{2}{*}[47]{} \\
\hline & rs13017455 & & & CT reduces preeclampsia risk & \\
\hline \multirow[t]{2}{*}{$A C V R 2 A$} & rs1424954 & $613 / 693$ & Mother & $\begin{array}{l}\text { These SNPs were associated with the more severe early } \\
\text { onset preeclampsia }\end{array}$ & [104] \\
\hline & rs1801131 & $150 / 150$ & Mother & CC genotype increases risk & {$[105]$} \\
\hline \multirow[t]{3}{*}{ MTHFR } & \multirow{3}{*}{ rs1801133 } & $192 / 196$ & Mother & $\begin{array}{c}\text { The synergic (rs1801131+rs1801133) effect of MTHFR } \\
\text { variants could increase PE and EOPE risk }\end{array}$ & {$[106]$} \\
\hline & & $198 / 101$ & Mother & Increased risk & {$[107]$} \\
\hline & & $125 / 274$ & Mother & Protective effect & {$[108]$} \\
\hline$I L-1 B$ & rs1143630 & $169 / 287$ & Mother & "T" allele increase risk & [109] \\
\hline \multirow{2}{*}{ C6 } & rs7444800 & \multirow{5}{*}{$203 / 233$} & \multirow{5}{*}{ Mother } & \multirow{5}{*}{$\begin{array}{c}\text { Genetic variations in this gene increase risk, and the risk } \\
\text { varied by preeclampsia subtypes }\end{array}$} & \multirow{5}{*}[110]{} \\
\hline & rs4957381 & & & & \\
\hline \multirow{3}{*}{ MASP1 } & rs1108450 & & & & \\
\hline & rs3774282 & & & & \\
\hline & rs698106 & & & & \\
\hline$V E G F$ and & $\begin{array}{l}\text { VEGFR1 } \\
\text { rs722503 }\end{array}$ & \multirow[b]{2}{*}{$165 / 191$} & \multirow[b]{2}{*}{ Mother } & Increase risk after the age of 40 years & \multirow[b]{2}{*}{ [111] } \\
\hline VEGFR1 & $\begin{array}{c}\text { VEGFA } \\
\text { rs3025039 }\end{array}$ & & & $\mathrm{C}$ allele increase risk; $\mathrm{T}$ allele protective allele & \\
\hline \multirow[t]{3}{*}{$H L A-G$} & $\begin{array}{l}\text { rs17179101 and } \\
\quad \text { rs9380142 }\end{array}$ & $47 / 68$ & Mother & This SNP combination increases risk & {$[112]$} \\
\hline & HLA-G 0106G & $83 / 240$ & Mother & Increased risk & {$[113]$} \\
\hline & & $151 / 189$ & Mother & Increased risk & {$[44]$} \\
\hline \multirow[t]{2}{*}{$I L-10$} & rs1800896 & $134 / 164$ & Mother & Increased risk & {$[45]$} \\
\hline & & $101 / 91$ & Mother & AA allele increases risk & {$[46]$} \\
\hline ICOS & rs4675378 & $130 / 260$ & Mother & $\mathrm{T}$ allele and TT genotype protective allele & {$[114]$} \\
\hline \multirow[t]{2}{*}{ GSTP1 } & \multirow[t]{2}{*}{ rs1695 } & $\begin{array}{l}113 \text { trios } / 317(149 \\
\text { men, } 168 \text { women })\end{array}$ & $\begin{array}{l}\text { Mother/ } \\
\text { father/child }\end{array}$ & $\begin{array}{l}\text { This polymorphism in paternal and fetal GSTP1 gene } \\
\text { increases risk }\end{array}$ & {$[41]$} \\
\hline & & $125 / 274$ & Mother & G allele protective effect & {$[108]$} \\
\hline$T G F-B 1$ & rs1800470 & $175 / 253$ & Mother & TT genotype protective allele & {$[115]$} \\
\hline$I L-6$ & rs1800795 & $116 / 107$ & Mother & $\mathrm{C}$ allele protective allele & {$[116]$} \\
\hline$N L R P 1$ & rs12150220 & $286 / 309$ & Mother & Risk effect & [117] \\
\hline \multirow{2}{*}{ eNOS } & rs1799983 & $322 / 522$ & Mother & Risk effect & [118] \\
\hline & rs2297518 & $353 / 212$ & Mother & A allele increases risk & [119] \\
\hline$I L-1 A$ & rs3783550 & $79 / 210$ & Mother & A allele increases risk & {$[120]$} \\
\hline$A C E$ & rs1799752 & $66 / 37$ & Mother & DD genotype and D allele increase risk & {$[121]$} \\
\hline EDN1 & rs5370 & $61 / 49$ & $\begin{array}{l}\text { Mother/ } \\
\text { father }\end{array}$ & rs5370 SNP protective effect & {$[122]$} \\
\hline ERAP2 & rs 2549782 & $528 / 575$ & $\begin{array}{l}\text { Mother and } \\
\text { neonates }\end{array}$ & Risk effect & {$[123]$} \\
\hline GSTM1 & rs4025935 & Mother & $112 / 233$ & GSTT1 deletion and combined GSTM1/GSTT1 deletion & [12 \\
\hline GSTT1 & rs71748309 & Mother & $112 / 233$ & increase risk & [124] \\
\hline
\end{tabular}

statistical significance. Combining genome-wide studies with the candidate gene approaches in other population samples, subsequently validating the findings would increase the statistical power to identify potential genes useful for diagnosis. Given the genetic heterogeneity of the disease and the variation between different ethnic populations, it is difficult to identify a unique gene.

\section{4. miRNAs}

miRNAs are small noncoding RNA of 18-22 nucleotides which are involved in post-transcriptional regulation. Since its discovery in 1993, miRNAs have been described in numerous biological processes, such as proliferation, cell growth, and embryogenesis [60,61]. miRNAs can induce 
TABLE 2: Genes associated with preeclampsia by GWAS.

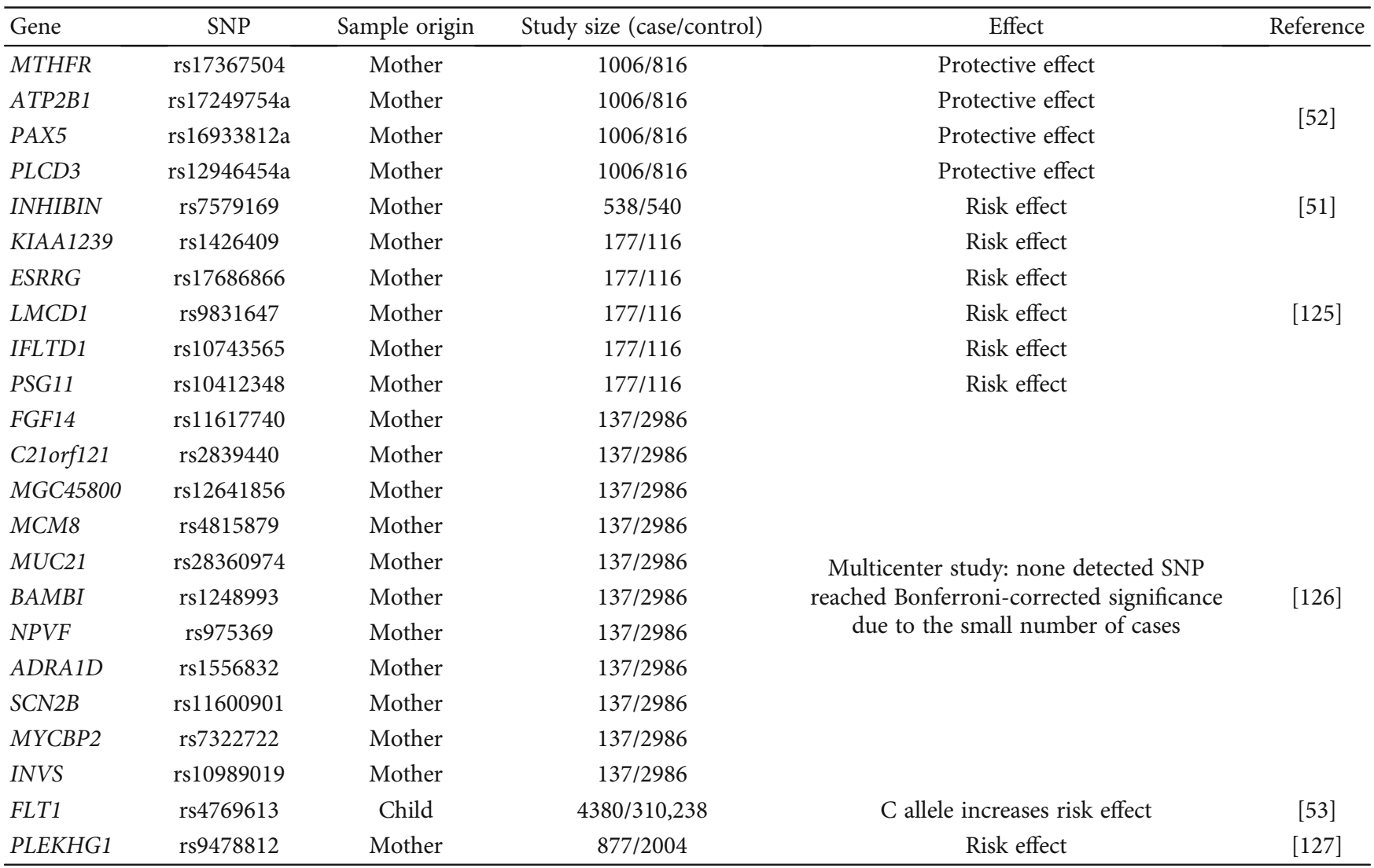

mRNA destabilization and/or inhibition of translation. miRNAs play an important role in cellular life, as it has been demonstrated that the loss of miRNA biogenesis is lethal during embryonic development $[62,63]$. The molecular mechanisms have been well described. RNA pol II is involved in the synthesis of miRNAs in pre-miRNA. The latter undergoes a maturation process by Drosha/DGCR8 in pre-miRNA, exported from the nucleus into the cytoplasm through exportin-5. This pre-miRNA is processed by the DICER enzyme into the miRNA duplex, and finally, one of the two strands is incorporated into a complex, the RNAinduced silencing complex (RISC). This complex can bind to a specific $3^{\prime}$ UTR to play its role in regulating mRNA posttranscription [64].

Given the principal role of miRNAs in controlling mRNA expression, it is not surprising that the dysregulation of their expression leads to the loss of cellular homeostasis and consequently to disease emergence. Different studies have revealed the involvement of miRNAs in the regulation of placental function and development. The evolution of miRNA expression analysis techniques has helped to describe and/or understand miRNA function in healthy placentas. Dysregulation of miRNA expression has been reported in several diseases and more specifically in $\mathrm{PE}$ [65-69]. There are more than 2000 miRNAs in the human genome, and it is estimated that over 382 miRNAs are expressed in trophoblasts isolated from normal human placenta $[64,70]$.

$\mathrm{PE}$, as described previously, is characterized by hypertension occurring after the twentieth week of pregnancy, and it is an important cause of maternal and child morbidity and mortality. Different molecular hypotheses have been proposed to explain the origin of this pathology, and recently, some miRNAs have been demonstrated to be involved in the syndrome due to the function of several miRNA clusters in the placenta.

C19MC, the largest cluster described, is composed of 46 miRNA genes that represent 59 mature miRNAs [71, 72]. C19MC miRNAs are highly expressed in the placenta, more precisely in trophoblasts, and in preeclampsia, a decrease in C19MC miRNA expression has been reported [73, 74]. It has been described that C19MC miRNA expression is increased from the first to third trimester of pregnancy under normal conditions [70]. Hromadnikova et al. in 2017 showed an increase in C19MC miRNA expression, more specifically miR-517-5p, miR-518b, and miR-520h in women with $\mathrm{PE}$ versus women with normal pregnancy [75]. Recently, Zhang et al. showed that a member of C19MC, miR-515-5p, targets and inhibits the expression of CYP19A1 and GCM1, among other genes important in trophoblast differentiation [76]. Besides, Xie et al. showed that C19MC miRNAs play an inhibitory role in trophoblast 
TABLe 3: Genes associated with PE by microarrays studies.

\begin{tabular}{|c|c|c|c|c|}
\hline Gene & Study size & Tissue & Fold change & Reference \\
\hline PRG2 & $4 / 4$ & \multirow{7}{*}{ Syncytiotrophoblast severe preeclampsia (placenta) } & 6.4 & \multirow{7}{*}[128]{} \\
\hline FSTL3 & $4 / 4$ & & 3.7 & \\
\hline FABP4 & $4 / 4$ & & 3.5 & \\
\hline RDH13 & $4 / 4$ & & 3.1 & \\
\hline PLAC1 & $4 / 4$ & & -3.4 & \\
\hline SERPINI1 & $4 / 4$ & & -4.4 & \\
\hline GSTA3 & $4 / 4$ & & -4.8 & \\
\hline CXCL8 & $3 / 4$ & \multirow{2}{*}{ Cytotrophoblast severe preeclampsia (placenta) } & 3.5 & \multirow{2}{*}[129]{} \\
\hline GH2 & $3 / 4$ & & -14.2 & \\
\hline$s F L T 1$ & $21 / 21$ & \multirow{11}{*}{ Placenta (full thickness) } & 2.6 & \multirow{2}{*}[58]{} \\
\hline$E N G$ & $23 / 37$ & & 1.852.919.237 & \\
\hline INHIBIN & $21 / 21$ & & 3.0 & \multirow[t]{9}{*}[58,130,131]{} \\
\hline SIAE & $23 / 37$ & & 1.354 .912 .795 & \\
\hline PAPPA2 & $21 / 21$ & & 2.9 & \\
\hline BRSK2 & $21 / 21$ & & 8.6 & \\
\hline FLJ90650 & $21 / 21$ & & 10.0 & \\
\hline$L E P$ & $21 / 21$ & & 40.0 & \\
\hline$L H B$ & $21 / 21$ & & 4.1 & \\
\hline$P D G F D$ & $21 / 21$ & & -2.3 & \\
\hline COX17 & $21 / 21$ & & -4.3 & \\
\hline HS3ST2 & $60 / 65$ & \multirow{9}{*}{ Maternal placenta (decidua basalis) } & -1.39 & \multirow{9}{*}[130]{} \\
\hline TNFRSF14 & $60 / 65$ & & -1.35 & \\
\hline SLC2A6 & $60 / 65$ & & -1.32 & \\
\hline$D P P 7$ & $60 / 65$ & & -1.22 & \\
\hline CD72 & $60 / 65$ & & -1.21 & \\
\hline PER3 & $60 / 65$ & & -1.20 & \\
\hline$D B P$ & $60 / 65$ & & -1.20 & \\
\hline PDK4 & $60 / 65$ & & 1.72 & \\
\hline HS3ST2 & $60 / 65$ & & -1.39 & \\
\hline COL17A1 & $6 / 6$ & \multirow{9}{*}{ Placental biopsies } & 6.6 & \multirow{9}{*}[56]{} \\
\hline KRT2 & $6 / 6$ & & 6.4 & \\
\hline NCAM1 & $6 / 6$ & & 3.8 & \\
\hline$P K P 2$ & $6 / 6$ & & 3.2 & \\
\hline$B M P 2$ & $6 / 6$ & & -3.9 & \\
\hline $\mathrm{CDH} 3$ & $6 / 6$ & & -4.3 & \\
\hline LEP OB/OBS & $6 / 6$ & & 43.6 & \\
\hline$M E F 2 A$ & $6 / 6$ & & 3.9 & \\
\hline MUC1 & $6 / 6$ & & 3.6 & \\
\hline
\end{tabular}

migration [73]. Probably, the increase of the last ones is dysregulated and can induce a decontrolled inhibition of trophoblasts migration. Furthermore, the generation of C19MC double homozygous transgenic mice lead to C19MC miRNA overexpression [132] causing a change of expression of mRNAs involved in cell migration as Mmpla or Prl5a1. These expression changes probably conduce to malformation of the placenta spotted by an irregular boundary between the labyrinthine layer and the junctional zone. The authors confirmed these observations by using probes for Tpbpb and Ceacam11 (more expressed in spongiotrophoblast cells) invagination of spongiotrophoblast cells in the labyrinth layer [73], which supports the important role of C19MC miRNAs in cell migration regulation. Interestingly, C19MC is expressed from the paternal chromosome, while C14MC, another large miRNA cluster located on the chromosome $14 \mathrm{q} 32$ locus, is expressed from the maternal chromosome $[77,78]$. The last one contains 52 miRNAs, and different studies have shown the importance of $\mathrm{C} 14 \mathrm{MC}$ in placentation. In a mouse model, the $\mathrm{KO}$ of 
miR-127 affects the regulation of Rtll, which disturbs placental development [79]. Furthermore, trophoblast proliferation, invasion, and migration are regulated by miR-378a-5p and miR-376c, among others. The expression of these miRNAs was downregulated in women with PE. miR-378a-5p directly targets and represses the expression of NODAL proteins [80]. miR-376c is involved in the inhibition of NODAL signalling by targeting ALK5 and ALK7, proteins that are important in this pathway [81]. These results suggest that dysregulation of NODAL by miRNAs can prevent trophoblast migration, invasion, and proliferation in women with PE.

Furthermore, other studies have shown a disturbance of miRNA expression in PE, and their functions are well documented. Among these, compromise of processes such as cell cycle, migration, and angiogenesis can explain the PE phenotype [82]. Recently, some researchers have found variants in the $3^{\prime} \mathrm{UTR}$ of PTX3, RGS2, and MTHFR genes, which are associated with PE [83-85]. The involvement of these proteins in PE has been previously described. The decrease in RGS2 expression contributes to PE through its inhibitory function on arterial pressure regulation [89], and PTX3 is involved in the regulation of inflammation and is upregulated in women with PE [86]. Variants in MTHFR can induce a decrease in the enzymatic activity that increases folate levels, which contributes to PE [87]. Variants in the $3^{\prime}$ UTR may cause dysregulation of gene expression through loss or gain of miRNA recognition, as has been described for other diseases such as epilepsy [88] and venous thrombosis [133], and as a susceptibility factor in cancer [90-92]. PE is a multifactorial disease for which the genetic load induces the PE phenotype, and the analysis of noncoding region as $3^{\prime}$ UTR can help to better understand the syndrome.

\section{Unconventional Therapeutic Strategies in Preeclampsia}

In addition to traditional medical management for preeclampsia, other forms of treatment have been proposed and open a future with new perspectives of control for the signs and symptoms of this disease, as well as for the prevention of maternal and fetal comorbidities triggered by preeclampsia.

5.1. Mitochondrial Antioxidant Therapy. Excessive production of reactive oxygen species (ROS) has been linked to pathological processes such as preeclampsia, secondary to the altered placentation that occurs in this disease, which triggers an increased inflammatory response and endothelial dysfunction. Different sources of ROS have been identified in the placenta, among which mitochondrial dysfunction may be related, and this alteration has been linked to the increased production of these compounds in the pathophysiology of preeclampsia [93].

Mitochondria-targeted antioxidants have been proposed as a treatment to reverse the effects of mitochondrial oxidative stress in the placenta. The use of the mitochondrial-specific hydrogen sulfide donor AP39 in cellular models has been shown to prevent ROS production and reverse mitochondrial oxidative stress, thereby decreasing the activation of hypoxia-inducible transcription factors such as HIF- $1 \alpha$, as well as enhancing cytochrome $\mathrm{C}$ oxidase levels and reversing the antiangiogenic response in hypoxic trophoblast cells. However, further studies are required to demonstrate whether the effects of AP39 can improve symptomatology in animal models of preeclampsia [94].

5.2. Ligands of sFLT1 as a Therapeutic Target. Overexpression of the antiangiogenic factor sFLT1 (vascular endothelial growth factor receptor 1) has been linked to production of endothelial damage characteristic of preeclampsia, proteinuria, hypertension, and target organ damage. Several studies have identified sFLT1 as a therapeutic target for the management of preeclampsia [95]. In primate animal models, for example, the recombinant sFLT1 ligand placental growth factor (PlGF) has been shown to reduce blood pressure and proteinuria levels compared to untreated preeclamptic controls. In the case of VEGF121, another recombinant ligand of sFLT1, this factor showed improvement in preeclampsia-related symptomatology in animal models [96]. Therefore, the use of these strategies offers an alternative for the management and control of the symptomatology attributed to PE, which could lead to an improvement in the associated morbidity and mortality.

5.3. RNAi in Animal Models. Preeclampsia pathogenesis has been associated with dysfunction of the renin-angiotensinaldosterone (R-A-A) axis, resulting in decreased renin levels, increased angiotensin-converting enzyme (ACE) activity, decreased angiotensin II levels, and increased response to this enzyme. This axis has been implicated in the regulation of blood pressure and water-electrolyte balance, and its components are expressed among other tissues, in spiral arteries, human placenta, and fetal tissues; therefore, alterations in this axis represent a risk factor for the development of $\mathrm{PE}$ [97]. Some mutations on the R-A-A axis have been associated with preeclampsia, as in the case of the missense mutation in the AGT (angiotensin) gene M235T, which was associated with elevated plasma levels of AGT in carriers of this variant [98].

The use of RNAi directed against maternal hepatic TGA offers an alternative for the symptomatic control of preeclampsia in two animal models tested by German investigators. In one of these models, female mice expressing human Agt were crossed with male mice expressing human renin, which resulted in the upregulation of the R-A-A axis at central circulatory and uteroplacental levels. In the second model, the researchers surgically decreased uterine perfusion pressure and thus induced placental ischemia, which secondarily produced alteration of the R-A-A axis with hypertension, oxidative stress, excess of inflammatory factors at the circulatory level, and decreased glomerular function. They found that the use of siRNA in the two animal models produced an improvement in the signs and symptoms characteristic of preeclampsia, with reduction of blood pressure, improvement of renal function, and intrauterine growth 
restriction (IUGR) patterns. [99]. With further studies, this result might open an opportunity to add new tools to avoid complications caused by preeclampsia.

5.4. PP13 as a Future Tool in Preelampsia Management. Galectins are a family of carbohydrate binding proteins with affinity to $\beta$-galactoside sugars, and one of them, Galectin 13 , also known as protein 13 (PP13), is expressed by the syncytiotrophoblast and detected since early stages of pregnancy. This protein has been associated with critical processes of pregnancy such as placental implantation and vascular transformation [100]. In a functional in vivo study using pregnant rats, the authors demonstrated that intravenous injections of PP13 could reduce blood pressure [101]. Also, a subsequent study with implantation of osmotic pumps in nongravid rats injected subcutaneously with recombinant PP13 (rPP13) showed that uterine vessels expanded significantly, demonstrating that PP13 could have an important role as a future tool in the treatment of PE $[102,103]$.

\section{Conclusion}

Preeclampsia is a complex disease constituting a serious public health problem. Numerous published studies on the subject have described different genes involved in the molecular etiopathology of this disease; nevertheless, to date, no universal genes have been described. Furthermore, since the last decade, miRNAs have been described to be involved in the molecular mechanism of the disease. The complexity of multifactorial diseases makes it difficult to resolve and find a treatment, and there is still much to be discovered about the pathophysiology and treatment of this illness. Importantly, the majority of studies have been focused on the coding region of candidate genes, neglecting noncoding sequences, such as promoters and/or untranslated regions. These sequences might be critical to understanding the role of genetic factors in PE.

\section{Ethical Approval}

This work did not need ethic committee approval since the study is a bibliographic review.

\section{Conflicts of Interest}

There are no conflicts of interest.

\section{Acknowledgments}

The author, Luisa Fernanda Castillo-Léon, was financed by the postdoctoral fellowship "Convocatoria Programa de Estancias Postdoctorales 811-2018" of MinCiencias Colombia.

\section{References}

[1] S. Agrawal, S. Shinar, A. S. Cerdeira, C. Redman, and M. Vatish, "Predictive performance of PlGF (placental growth factor) for screening preeclampsia in asymptomatic women: a systematic review and meta-analysis," Hypertension, vol. 74, no. 5, pp. 1124-1135, 2019.

[2] B. W. J. Mol, C. T. Roberts, S. Thangaratinam, L. A. Magee, and G. J. Hofmeyr, "Pre-eclampsia," The Lancet, vol. 387, no. 10022, pp. 999-1011, 2016.

[3] M. A. Brown, L. A. Magee, L. C. Kenny et al., "The hypertensive disorders of pregnancy: ISSHP classification, diagnosis \& management recommendations for international practice," Pregnancy Hypertension, vol. 13, pp. 291-310, 2018.

[4] T. Chaiworapongsa, P. Chaemsaithong, L. Yeo, and R. Romero, "Pre-eclampsia part 1: current understanding of its pathophysiology," Nature Reviews. Nephrology, vol. 10, pp. 466-480, 2014.

[5] American College of Obstetricians and Gynecologists and American College of Obstetricians and Gynecologists, Hypertension in pregnancy, American College of Obstetricians and Gynecologists, 2013.

[6] A. Acharya, W. Brima, S. Burugu, and T. Rege, "Prediction of preeclampsia-bench to bedside," Current Hypertension Reports, vol. 16, p. 491, 2014.

[7] F. J. Valenzuela, A. Pérez-Sepúlveda, M. J. Torres, P. Correa, G. M. Repetto, and S. E. Illanes, "Pathogenesis of preeclampsia: the genetic component," Journal of Pregnancy, vol. 2012, Article ID 632732, 8 pages, 2012.

[8] P. J. Correa, Y. Palmeiro, M. J. Soto, C. Ugarte, and S. E. Illanes, "Etiopathogenesis, prediction, and prevention of preeclampsia," Hypertension in Pregnancy, vol. 35, pp. 280294, 2016.

[9] A. C. Staff, "The two-stage placental model of preeclampsia: an update," Journal of Reproductive Immunology, vol. 134, pp. 1-10, 2019.

[10] R. T. Michita, V. D. Kaminski, and J. A. Chies, "Genetic variants in preeclampsia: lessons from studies in LatinAmerican populations," Frontiers in Physiology, vol. 9, p. 1771, 2018.

[11] F. R. Helmo, A. M. Lopes, A. C. Carneiro et al., "Angiogenic and antiangiogenic factors in preeclampsia," PathologyResearch and Practice, vol. 214, pp. 7-14, 2018.

[12] R. Marín, D. I. Chiarello, C. Abad, D. Rojas, F. Toledo, and L. Sobrevia, "Oxidative stress and mitochondrial dysfunction in early-onset and late-onset preeclampsia," Biochimica et Biophysica Acta - Molecular Basis of Disease, vol. 1866, article 165961, 2020.

[13] S. Roberge, E. Bujold, and K. H. Nicolaides, “Aspirin for the prevention of preterm and term preeclampsia: systematic review and metaanalysis," American Journal of Obstetrics and Gynecology, vol. 218, pp. 287-293.e1, 2018.

[14] S. Chappell and L. Morgan, "Searching for genetic clues to the causes of pre-eclampsia," Clinical Science, vol. 110, no. 4, pp. 443-458, 2006.

[15] A. Sutherland, D. W. Cooper, P. W. Howie, W. A. Liston, and I. MacGillivray, "The indicence of severe pre-eclampsia amongst mothers and mothers-in-law of pre-eclamptics and controls," British Journal of Obstetrics and Gynaecology, vol. 88, pp. 785-791, 1981.

[16] R. Arngrimsson, S. Björnsson, R. T. Geirsson, H. Björnsson, J. J. Walker, and G. Snaedal, "Genetic and familial predisposition to eclampsia and pre-eclampsia in a defined population," British Journal of Obstetrics and Gynaecology, vol. 97, pp. 762-769, 1990. 
[17] I. Mogren, U. Högberg, A. Winkvist, and H. Stenlund, "Familial occurrence of preeclampsia," Epidemiology, vol. 10, pp. 518-522, 1999.

[18] S. Mütze, S. Rudnik-Schöneborn, K. Zerres, and W. Rath, "Genes and the preeclampsia syndrome," Journal of Perinatal Medicine, vol. 36, pp. 38-58, 2008.

[19] M. P. Johnson, E. Fitzpatrick, T. D. Dyer et al., "Identification of two novel quantitative trait loci for pre-eclampsia susceptibility on chromosomes $5 \mathrm{q}$ and $13 \mathrm{q}$ using a variance components-based linkage approach," Molecular Human Reproduction, vol. 13, pp. 61-67, 2007.

[20] E. Nilsson, H. Salonen Ros, S. Cnattingius, and P. Lichtenstein, "The importance of genetic and environmental effects for pre-eclampsia and gestational hypertension: a family study," BJOG: An International Journal of Obstetrics \& Gynaecology, vol. 111, pp. 200-206, 2004.

[21] H. Salonen Ros, P. Lichtenstein, L. Lipworth, and S. Cnattingius, "Genetic effects on the liability of developing pre-eclampsia and gestational hypertension," American Journal of Medical Genetics, vol. 91, pp. 256-260, 2000.

[22] S. Cnattingius, M. Reilly, Y. Pawitan, and P. Lichtenstein, "Maternal and fetal genetic factors account for most of familial aggregation of preeclampsia: a population-based Swedish cohort study," American Journal of Medical Genetics. Part A, vol. 130A, pp. 365-371, 2004.

[23] H. E. J. Yong, P. Murthi, S. P. Brennecke, and E. K. Moses, "Genetic approaches in preeclampsia," Preeclampsia, vol. 1710, pp. 53-72, 2018.

[24] M. L. Wilson, T. M. Goodwin, V. L. Pan, and S. A. Ingles, "Molecular epidemiology of preeclampsia," Obstetrical \& Gynecological Survey, vol. 58, no. 1, pp. 39-66, 2003.

[25] A. M. A. Lachmeijer, G. A. Dekker, G. Pals, J. G. Aarnoudse, L. P. ten Kate, and R. Arngrímsson, "Searching for preeclampsia genes: the current position," European Journal of Obstetrics, Gynecology, and Reproductive Biology, vol. 105, pp. 94-113, 2002.

[26] A. M. Lachmeijer, R. Arngrímsson, E. J. Bastiaans et al., "A genome-wide scan for preeclampsia in the Netherlands," European Journal of Human Genetics, vol. 9, no. 10, pp. 758-764, 2001.

[27] A. J. Buurma, R. J. Turner, J. H. M. Driessen et al., "Genetic variants in pre-eclampsia: a meta-analysis," Human Reproduction Update, vol. 19, pp. 289-303, 2013.

[28] E. Staines-Urias, M. C. Paez, P. Doyle et al., "Genetic association studies in pre-eclampsia: systematic meta-analyses and field synopsis," International Journal of Epidemiology, vol. 41, pp. 1764-1775, 2012.

[29] B. Dai, T. Liu, B. Zhang, X. Zhang, and Z. Wang, "The polymorphism for endothelial nitric oxide synthase gene, the level of nitric oxide and the risk for pre-eclampsia: a meta-analysis," Gene, vol. 519, pp. 187-193, 2013.

[30] C. K. H. Yu, J. P. Casas, M. D. Savvidou, M. K. Sahemey, K. H. Nicolaides, and A. D. Hingorani, "Endothelial nitric oxide synthase gene polymorphism (Glu298Asp) and development of pre-eclampsia: a case-control study and a meta-analysis," BMC Pregnancy and Childbirth, vol. 6, no. 1, p. 7, 2006.

[31] T. Groten, E. Schleussner, T. Lehmann et al., "eNOSI4 and EPHX1 polymorphisms affect maternal susceptibility to preeclampsia: analysis of five polymorphisms predisposing to cardiovascular disease in 279 Caucasian and 241 African women," Archives of Gynecology and Obstetrics, vol. 289, pp. 581-593, 2014.

[32] I. Sari, H. Pinarbasi, E. Pinarbasi, and C. Yildiz, “Association between the soluble epoxide hydrolase gene and preeclampsia," Hypertension in Pregnancy, vol. 36, pp. 315-325, 2017.

[33] P. J. Williams and F. Broughton Pipkin, "The genetics of preeclampsia and other hypertensive disorders of pregnancy," Best Practice \& Research. Clinical Obstetrics \& Gynaecology, vol. 25, pp. 405-417, 2011.

[34] L. M. Procopciuc, G. Zaharie, G. Caracostea, and F. Stamatian, "Newborn LpL (Ser447Stop, Asn291Ser) genotypes and the interaction with maternal genotypes influence the risk for different types of preeclampsia: modulating effect on lipid profile and pregnancy outcome," Gynecological Endocrinology, vol. 30, no. 3, pp. 221-225, 2014.

[35] K. Matsubara, T. Higaki, Y. Matsubara, and A. Nawa, "Nitric oxide and reactive oxygen species in the pathogenesis of preeclampsia," International Journal of Molecular Sciences, vol. 16, pp. 4600-4614, 2015.

[36] S. Gupta, N. Aziz, L. Sekhon et al., "Lipid peroxidation and antioxidant status in preeclampsia: a systematic review," Obstetrical \& Gynecological Survey, vol. 64, pp. 750-759, 2009.

[37] F. M. Fong, M. K. Sahemey, G. Hamedi et al., "Maternal genotype and severe preeclampsia: a HuGE review," American Journal of Epidemiology, vol. 180, pp. 335-345, 2014.

[38] X. Wang, T. Bai, S. Liu, H. Pan, and B. Wang, "Association between thrombophilia gene polymorphisms and preeclampsia: a meta-analysis," PLoS One, vol. 9, article e100789, 2014.

[39] X. Wang, H. Wu, and X. Qiu, "Methylenetetrahydrofolate reductase (MTHFR) gene C677T polymorphism and risk of preeclampsia: an updated meta-analysis based on 51 studies," Archives of Medical Research, vol. 44, pp. 159-168, 2013.

[40] P. Andraweera, S. Thompson, V. Zhang, R. Nowak, G. Dekker, and C. Roberts, "22: maternal, paternal and fetal single nucleotide polymorphisms in vascular endothelial growth factor family genes associate with pregnancy complications," American Journal of Obstetrics and Gynecology, vol. 201, p. S13, 2009.

[41] P. L. M. Zusterzeel, M. T. M. Raijmakers, E. M. Roes, W. H. M. Peters, and E. Steegers, "Paternal contribution to the risk for pre-eclampsia," Journal of Medical Genetics, vol. 39, no. 1, pp. 44-45, 2002.

[42] Q. E. Harmon, S. M. Engel, M. C. Wu et al., "Polymorphisms in inflammatory genes are associated with term small for gestational age and preeclampsia," American Journal of Reproductive Immunology, vol. 71, no. 5, pp. 472-484, 2014.

[43] F. Mohajertehran, J. Tavakkol Afshari, Z. Rezaieyazdi, and N. Ghomian, "Association of single nucleotide polymorphisms in the human tumor necrosis factor- $\alpha$ and interleukin $1-\beta$ genes in patients with pre-eclampsia," Iranian Journal of Allergy, Asthma, and Immunology, vol. 11, no. 3, pp. 224-229, 2012.

[44] S. Daher, N. Sass, L. G. Oliveira, and R. Mattar, "Cytokine genotyping in preeclampsia," American Journal of Reproductive Immunology, vol. 55, no. 2, pp. 130-135, 2006.

[45] E. Kamali-Sarvestani, S. Kiany, B. Gharesi-Fard, and M. Robati, "Association study of IL-10 and IFN-gamma gene polymorphisms in Iranian women with preeclampsia," Journal of Reproductive Immunology, vol. 72, pp. 118-126, 2006. 
[46] P. Vural, S. Degirmencioglu, N. Y. Saral et al., "Tumor necrosis factor alpha, interleukin- 6 and interleukin-10 polymorphisms in preeclampsia," The Journal of Obstetrics and Gynaecology Research, vol. 36, pp. 64-71, 2010.

[47] P. Chen, Y. Gong, Y. Pu et al., "Association between polymorphisms in IL-27 gene and pre-eclampsia," Placenta, vol. 37, pp. 61-64, 2016.

[48] B. Liu, Y. Li, Y. Yao et al., "Polymorphisms of the IL27 gene in a Chinese Han population complicated with pre-eclampsia," Scientific Reports, vol. 6, no. 1, article 23029, 2016.

[49] E. K. Moses, E. Fitzpatrick, K. A. Freed et al., "Objective prioritization of positional candidate genes at a quantitative trait locus for pre-eclampsia on 2q22," Molecular Human Reproduction, vol. 12, pp. 505-512, 2006.

[50] M. van Dijk, J. Mulders, A. Poutsma et al., "Maternal segregation of the Dutch preeclampsia locus at 10q22 with a new member of the winged helix gene family," Nature Genetics, vol. 37, pp. 514-519, 2005.

[51] M. P. Johnson, S. P. Brennecke, C. E. East et al., "Genomewide association scan identifies a risk locus for preeclampsia on 2q14, near the inhibin, beta B gene," PLoS One, vol. 7, no. 3, article e33666, 2012.

[52] L. C. V. Thomsen, N. S. McCarthy, P. E. Melton et al., "The antihypertensive MTHFR gene polymorphism rs17367504-G is a possible novel protective locus for preeclampsia," Journal of Hypertension, vol. 35, no. 1, pp. 132-139, 2017.

[53] R. McGinnis, V. Steinthorsdottir, N. O. Williams et al., "Variants in the fetal genome near FLT1 are associated with risk of preeclampsia," Nature Genetics, vol. 49, no. 8, pp. 1255-1260, 2017.

[54] T. Hod, A. S. Cerdeira, and S. A. Karumanchi, "Molecular mechanisms of preeclampsia," Cold Spring Harbor Perspectives in Medicine, vol. 5, no. 10, article a023473, 2015.

[55] T. Kikas, R. Inno, K. Ratnik, K. Rull, and M. Laan, "C-Allele of rs4769613 NearFLT1Represents a high-confidence placental risk factor for preeclampsia," Hypertension, vol. 76, no. 3, pp. 884-891, 2020.

[56] T. Reimer, D. Koczan, B. Gerber, D. Richter, H. J. Thiesen, and K. Friese, "Microarray analysis of differentially expressed genes in placental tissue of pre-eclampsia: up-regulation of obesity-related genes," Molecular Human Reproduction, vol. 8, pp. 674-680, 2002.

[57] Z. J. Pang and F. Q. Xing, "Expression profile of trophoblast invasion-associated genes in the pre-eclamptic placenta," British Journal of Biomedical Science, vol. 60, pp. 97-101, 2003.

[58] S. Tsai, N. E. Hardison, A. H. James et al., "Transcriptional profiling of human placentas from pregnancies complicated by preeclampsia reveals disregulation of sialic acid acetylesterase and immune signalling pathways," Placenta, vol. 32, pp. 175-182, 2011.

[59] I. Iglesias-Platas, D. Monk, J. Jebbink et al., "STOX1 is not imprinted and is not likely to be involved in preeclampsia," Nature Genetics, vol. 39, pp. 279-280, 2007.

[60] R. C. Lee, R. L. Feinbaum, and V. Ambros, “The C. elegans heterochronic gene lin-4 encodes small RNAs with antisense complementarity to lin-14," Cell, vol. 75, pp. 843-854, 1993.

[61] L. F. R. Gebert and I. J. MacRae, "Regulation of microRNA function in animals," Nature Reviews. Molecular Cell Biology, vol. 20, no. 1, pp. 21-37, 2019.
[62] E. Bernstein, S. Y. Kim, M. A. Carmell et al., "Dicer is essential for mouse development," Nature Genetics, vol. 35, pp. 215217, 2003.

[63] Y. Wang, R. Medvid, C. Melton, R. Jaenisch, and R. Blelloch, "DGCR8 is essential for microRNA biogenesis and silencing of embryonic stem cell self-renewal," Nature Genetics, vol. 39, pp. 380-385, 2007.

[64] S. M. Hammond, "An overview of microRNAs," Advanced Drug Delivery Reviews, vol. 87, pp. 3-14, 2015.

[65] W. D. Nadim, V. Simion, H. Benedetti, C. Pichon, P. Baril, and S. Morisset-Lopez, "MicroRNAs in neurocognitive dysfunctions: new molecular targets for pharmacological treatments?," Current Neuropharmacology, vol. 15, pp. 260-275, 2017.

[66] C. N. Weiss and K. Ito, "A macro view of microRNAs: the discovery of microRNAs and their role in hematopoiesis and hematologic disease," International Review of Cell and Molecular Biology, vol. 334, pp. 99-175, 2017.

[67] T. A. Farazi, J. I. Hoell, P. Morozov, and T. Tuschl, "MicroRNAs in human cancer," Advances in Experimental Medicine and Biology, vol. 774, pp. 1-20, 2013.

[68] X.-Q. Hu and L. Zhang, "MicroRNAs in uteroplacental vascular dysfunction,” Cells, vol. 8, no. 11, p. 1344, 2019.

[69] G. Skalis, V. Katsi, A. Miliou et al., "MicroRNAs in preeclampsia," Microrna, vol. 8, no. 1, pp. 28-35, 2019.

[70] D. M. Morales-Prieto, W. Chaiwangyen, S. Ospina-Prieto et al., "MicroRNA expression profiles of trophoblastic cells," Placenta, vol. 33, pp. 725-734, 2012.

[71] E. C. Malnou, D. Umlauf, M. Mouysset, and J. Cavaillé, "Imprinted microRNA gene clusters in the evolution, development, and functions of mammalian placenta," Frontiers in Genetics, vol. 9, 2019.

[72] Y. Ouyang, J.-F. Mouillet, C. B. Coyne, and Y. Sadovsky, "Review: placenta-specific microRNAs in exosomes - good things come in nano-packages," Placenta, vol. 35, pp. S69S73, 2014.

[73] L. Xie, J.-F. Mouillet, T. Chu et al., "C19MC microRNAs regulate the migration of human trophoblasts," Endocrinology, vol. 155, pp. 4975-4985, 2014.

[74] I. Hromadnikova, K. Kotlabova, M. Ondrackova et al., "Expression profile of C19MC microRNAs in placental tissue in pregnancy-related complications," DNA and Cell Biology, vol. 34, pp. 437-457, 2015.

[75] I. Hromadnikova, K. Kotlabova, K. Ivankova, and L. Krofta, "First trimester screening of circulating C19MC microRNAs and the evaluation of their potential to predict the onset of preeclampsia and IUGR," PLoS One, vol. 12, article e0171756, 2017.

[76] M. Zhang, S. Muralimanoharan, A. C. Wortman, and C. R. Mendelson, "Primate-specific miR-515 family members inhibit key genes in human trophoblast differentiation and are upregulated in preeclampsia," Proceedings of the National Academy of Sciences, vol. 113, pp. E7069-E7076, 2016.

[77] M. Noguer-Dance, S. Abu-Amero, M. Al-Khtib et al., "The primate-specific microRNA gene cluster (C19MC) is imprinted in the placenta," Human Molecular Genetics, vol. 19, pp. 3566-3582, 2010.

[78] G. N. Valbuena, S. Apostolidou, R. Roberts et al., "The 14q32 maternally imprinted locus is a major source of longitudinally stable circulating microRNAs as measured by small RNA sequencing," Scientific Reports, vol. 9, p. 15787, 2019. 
[79] M. Ito, A. N. Sferruzzi-Perri, C. A. Edwards et al., "A transhomologue interaction between reciprocally imprinted miR127 and Rtll regulates placenta development," Development, vol. 142, no. 14, pp. 2425-2430, 2015.

[80] L. Luo, G. Ye, L. Nadeem et al., "MicroRNA-378a-5p promotes trophoblast cell survival, migration and invasion by targeting nodal," Journal of Cell Science, vol. 125, pp. 31243132, 2012.

[81] G. Fu, G. Ye, L. Nadeem et al., "MicroRNA-376c impairs transforming growth factor- $\beta$ and nodal signaling to promote trophoblast cell proliferation and invasion," Hypertension, vol. 61, no. 4, pp. 864-872, 2013.

[82] K. R. Bounds, V. L. Chiasson, L. J. Pan, S. Gupta, and P. Chatterjee, "MicroRNAs: new players in the pathobiology of preeclampsia," Frontiers in Cardiovascular Medicine, vol. 4, p. 60, 2017.

[83] T. Karppanen, T. Kaartokallio, M. M. Klemetti et al., “An RGS2 3'UTR polymorphism is associated with preeclampsia in overweight women," BMC Genetics, vol. 17, p. 121, 2016.

[84] N. Xu and W. Zhang, "PTX3 gene 3'UTR polymorphism and its interaction with environmental factors are correlated with the risk of preeclampsia in a Chinese Han population," Medicine (Baltimore), vol. 99, article e18740, 2020.

[85] A. Mohammadpour-Gharehbagh, S. Salimi, F. Keshavarzi et al., "Genetic variants in 3'-UTRs of MTHFR in the pregnancies complicated with preeclampsia and bioinformatics analysis," Journal of Cellular Biochemistry, vol. 119, pp. 773-781, 2018.

[86] Z. Xiong, X. Wang, S. Jiang, M. Jin, and W. Chen, “Association between pentraxin-3 and the risk of preeclampsia: a meta-analysis," Medicine, vol. 99, article e20744, 2020.

[87] B. Yang, S. Fan, X. Zhi et al., "Associations of MTHFR gene polymorphisms with hypertension and hypertension in pregnancy: a meta-analysis from 114 studies with 15411 cases and 21970 controls," PLoS One, vol. 9, article e87497, 2014.

[88] T. Li, Y. Kuang, and B. Li, “The genetic variants in 3' untranslated region of voltage-gated sodium channel alpha 1 subunit gene affect the mRNA-microRNA interactions and associate with epilepsy," BMC Genetics, vol. 17, 2016.

[89] K. J. Perschbacher, G. Deng, J. A. Sandgren et al., "Reduced mRNA expression of RGS2 (regulator of G protein signaling-2) in the placenta is associated with human preeclampsia and sufficient to cause features of the disorder in mice," Hypertension, vol. 75, no. 2, pp. 569-579, 2020.

[90] L. E. Skeeles, J. L. Fleming, K. L. Mahler, and A. E. Toland, “The impact of 3'UTR variants on differential expression of candidate cancer susceptibility genes," PLoS One, vol. 8, article e58609, 2013.

[91] S. E. Godshalk, T. Paranjape, S. Nallur et al., "A variant in a MicroRNA complementary site in the $3^{\prime}$ UTR of the KIT oncogene increases risk of acral melanoma," Oncogene, vol. 30, pp. 1542-1550, 2011.

[92] B. W. Kang, H.-S. Jeon, Y. S. Chae et al., "Impact of genetic variation in microRNA-binding site on susceptibility to colorectal cancer," Anticancer Research, vol. 36, pp. 3353-3361, 2016.

[93] V. R. Vaka, K. M. McMaster, M. W. Cunningham et al., "Role of mitochondrial dysfunction and reactive oxygen species in mediating hypertension in the reduced uterine perfusion pressure rat model of preeclampsia," Hypertension, vol. 72, no. 3, pp. 703-711, 2018.
[94] A. E. Covarrubias, E. Lecarpentier, A. Lo et al., "AP39, a modulator of mitochondrial bioenergetics, reduces antiangiogenic response and oxidative stress in hypoxia-exposed trophoblasts: relevance for preeclampsia pathogenesis," The American Journal of Pathology, vol. 189, pp. 104-114, 2019.

[95] E. Lemoine and R. Thadhani, "Affordable preeclampsia therapeutics," Trends in Pharmacological Sciences, vol. 40, pp. 85$87,2019$.

[96] Z. Li, Y. Zhang, J. Ying Ma et al., "Recombinant vascular endothelial growth factor 121 attenuates hypertension and improves kidney damage in a rat model of preeclampsia," Hypertension, vol. 50, no. 4, pp. 686-692, 2007.

[97] L. M. Procopciuc, G. Nemeti, E. Buzdugan, M. Iancu, F. Stamatian, and G. Caracostea, "Renin-angiotensin system gene variants and risk of early- and late-onset preeclampsia: a single center case-control study," Pregnancy Hypertens, vol. 18, pp. 1-8, 2019.

[98] K. Ward, A. Hata, X. Jeunemaitre et al., "A molecular variant of angiotensinogen associated with preeclampsia," Nature Genetics, vol. 4, no. 1, pp. 59-61, 1993.

[99] N. Haase, D. J. Foster, M. W. Cunningham et al., "RNA interference therapeutics targeting angiotensinogen ameliorate preeclamptic phenotype in rodent models," The Journal of Clinical Investigation, vol. 130, pp. 2928-2942, 2020.

[100] A. Soongsatitanon and V. Phupong, "Prediction of preeclampsia using first trimester placental protein 13 and uterine artery Doppler," The Journal of Maternal-Fetal \& Neonatal Medicine, 2020.

[101] S. Gizurarson, B. Huppertz, G. Osol, J. O. Skarphedinsson, M. Mandala, and H. Meiri, "Effects of placental protein 13 on the cardiovascular system in gravid and non-gravid rodents," Fetal Diagnosis and Therapy, vol. 33, pp. 257-264, 2013.

[102] T. Drobnjak, A. M. Jónsdóttir, H. Helgadóttir et al., "Placental protein 13 (PP 13) stimulates rat uterine vessels after slow subcutaneous administration," International Journal of Women's Health, vol. 11, pp. 213-222, 2019.

[103] M. Sammar, T. Drobnjak, M. Mandala, S. Gizurarson, B. Huppertz, and H. Meiri, "Galectin 13 (PP13) facilitates remodeling and structural stabilization of maternal vessels during pregnancy," International Journal of Molecular Sciences, vol. 20, p. 3192, 2019.

[104] L. C. Ferreira, C. E. M. Gomes, A. C. P. Araújo, P. F. Bezerra, P. Duggal, and S. M. B. Jeronimo, "Association between ACVR2A and early-onset preeclampsia: replication study in a northeastern Brazilian population," Placenta, vol. 36, pp. 186-190, 2015.

[105] P. Chedraui, D. Salazar-Pousada, A. Villao et al., "Polymorphisms of the methylenetetrahydrofolate reductase gene (C677T and A1298C) in nulliparous women complicated with preeclampsia," Gynecological Endocrinology, vol. 30, no. 5, pp. 392-396, 2014.

[106] S. Salimi, M. Saravani, M. Yaghmaei et al., "The early-onset preeclampsia is associated with MTHFR and FVL polymorphisms," Archives of Gynecology and Obstetrics, vol. 291, pp. 1303-1312, 2015.

[107] Z. Rahimi, S. Malek-Khosravi, Z. Rahimi, F. Jalilvand, and A. Parsian, "MTHFR C677T and eNOS G894T variants in preeclamptic women: contribution to lipid peroxidation and oxidative stress," Clinical Biochemistry, vol. 46, pp. 143-147, 2013. 
[108] P. Canto, T. Canto-Cetina, R. Juárez-Velázquez et al., "Methylenetetrahydrofolate reductase C677T and glutathione Stransferase P1 A313G are associated with a reduced risk of preeclampsia in Maya-Mestizo women," Hypertension Research, vol. 31, no. 5, pp. 1015-1019, 2008.

[109] L. P. Leme Galvão, F. E. Menezes, C. Mendonca et al., “Analysis of association of clinical aspects and IL1B tagSNPs with severe preeclampsia," Hypertension in Pregnancy, vol. 35, pp. 112-122, 2016.

[110] W. Wu, H. Yang, Y. Feng et al., "Polymorphisms in complement genes and risk of preeclampsia in Taiyuan, China," Inflammation Research, vol. 65, no. 10, pp. 837-845, 2016.

[111] M. D. Amosco, V. A. M. Villar, J. M. A. Naniong, L. M. G. David-Bustamante, P. A. Jose, and C. P. Palmes-Saloma, "VEGF-A and VEGFR1 SNPs associate with preeclampsia in a Philippine population," Clinical and Experimental Hypertension, vol. 38, no. 7, pp. 578-585, 2016.

[112] K. Quach, S. A. Grover, S. Kenigsberg, and C. L. Librach, "A combination of single nucleotide polymorphisms in the $3^{\prime}$ untranslated region of HLA-G is associated with preeclampsia," Human Immunology, vol. 75, pp. 11631170, 2014.

[113] C. Y. Tan, J. F. V. Ho, Y. S. Chong et al., "Paternal contribution of HLA-G*0106 significantly increases risk for preeclampsia in multigravid pregnancies," Molecular Human Reproduction, vol. 14, pp. 317-324, 2008.

[114] K. P. T. Pendeloski, N. Sass, M. R. Torloni et al., "Immunoregulatory gene polymorphisms in women with preeclampsia," Hypertension Research, vol. 34, no. 3, pp. 384-388, 2011.

[115] M. Aguilar-Duran, J. Salvador-Moysén, C. Galaviz-Hernandez et al., "Haplotype analysis of TGF- $\beta 1$ gene in a preeclamptic population of northern Mexico," Pregnancy Hypertension: An International Journal of Women's Cardiovascular Health, vol. 4, no. 1, pp. 14-18, 2014.

[116] M. B. Pinheiro, K. B. Gomes, C. R. S. C. Ronda et al., "Severe preeclampsia: association of genes polymorphisms and maternal cytokines production in Brazilian population," Cytokine, vol. 71, pp. 232-237, 2015.

[117] A. Pontillo, E. C. Reis, P. N. Bricher et al., "NLRP1 L155H polymorphism is a risk factor for preeclampsia development," American Journal of Reproductive Immunology, vol. 73, no. 6, pp. 577-581, 2014.

[118] N. C. Serrano, J. P. Casas, L. A. Diaz et al., "Endothelial NO synthase genotype and risk of preeclampsia: a multicenter case-control study," Hypertension, vol. 44, no. 5, pp. 702707, 2004.

[119] L. M. Amaral, A. C. T. Palei, V. C. Sandrim et al., "Maternal iNOS genetic polymorphisms and hypertensive disorders of pregnancy," Journal of Human Hypertension, vol. 26, pp. 547-552, 2012.

[120] V. R. S. Silva, F. C. Soardi, S. C. S. V. Tanaka, R. L. da SilvaGrecco, M. C. Paschoini, and M. A. S. Balarin, "Investigation of polymorphisms in pre-eclampsia related genes VEGF and IL1A," Archives of Gynecology and Obstetrics, vol. 291, pp. 1029-1035, 2015.

[121] J. A. González-Garrido, J. R. García-Sánchez, J. M. TovarRodríguez, and I. M. Olivares-Corichi, "Preeclampsia is associated with ACE I/D polymorphism, obesity and oxidative damage in Mexican women," Pregnancy Hypertens, vol. 10, pp. 22-27, 2017.
[122] C. Galaviz-Hernandez, E. Arámbula-Meraz, D. Medina-Bastidas et al., "The paternal polymorphism rs 5370 in the EDN1 gene decreases the risk of preeclampsia," Pregnancy Hypertens, vol. 6, pp. 327-332, 2016.

[123] L. D. Hill, D. D. Hilliard, T. P. York et al., "Fetal ERAP2 variation is associated with preeclampsia in African Americans in a case-control study," BMC Medical Genetics, vol. 12, no. 1, p. 64, 2011.

[124] A. Sandoval-Carrillo, M. Aguilar-Duran, F. Vázquez-Alaniz et al., "Polymorphisms in the GSTT1 and GSTM1 genes are associated with increased risk of preeclampsia in the Mexican mestizo population," Genetics and Molecular Research, vol. 13, no. 1, pp. 2160-2165, 2014.

[125] L. Zhao, E. W. Triche, K. M. Walsh et al., "Genome-wide association study identifies a maternal copy-number deletion in PSG11 enriched among preeclampsia patients," BMC Pregnancy and Childbirth, vol. 12, no. 1, p. 61, 2012.

[126] L. Zhao, M. B. Bracken, and A. T. DeWan, "Genome-wide association study of pre-eclampsia detects novel maternal single nucleotide polymorphisms and copy-number variants in subsets of the Hyperglycemia and Adverse Pregnancy Outcome (HAPO) study cohort," Annals of Human Genetics, vol. 77, no. 4, pp. 277-287, 2013.

[127] K. J. Gray, V. P. Kovacheva, H. Mirzakhani et al., "Gene-centric analysis of preeclampsia identifies maternal association at PLEKHG1," Hypertension, vol. 72, no. 2, pp. 408-416, 2018.

[128] M. Gormley, K. Ona, M. Kapidzic, T. Garrido-Gomez, T. Zdravkovic, and S. J. Fisher, "Preeclampsia: novel insights from global RNA profiling of trophoblast subpopulations," American Journal of Obstetrics and Gynecology, vol. 217, no. 2, pp. 200.e1-200.e17, 2017.

[129] V. Sitras, R. H. Paulssen, H. Grønaas et al., "Differential placental gene expression in severe preeclampsia," Placenta, vol. 30, pp. 424-433, 2009.

[130] H. E. J. Yong, P. E. Melton, M. P. Johnson et al., "Genomewide transcriptome directed pathway analysis of maternal pre-eclampsia susceptibility genes," PLoS One, vol. 10, article e0128230, 2015.

[131] O. Brew, M. H. F. Sullivan, and A. Woodman, "Comparison of normal and pre-eclamptic placental gene expression: a systematic review with meta-analysis," PLoS One, vol. 11, article e0161504, 2016.

[132] J.-F. Mouillet, J. Goff, E. Sadovsky et al., “Transgenic expression of human C19MC miRNAs impacts placental morphogenesis," Placenta, vol. 101, pp. 208-214, 2020.

[133] C. Y. Vossen, V. A. van Hylckama, R. Teruel-Montoya et al., "Identification of coagulation gene 3'UTR variants that are potentially regulated by microRNAs," British Journal of Haematology, vol. 177, no. 5, pp. 782-790, 2017. 